\title{
TRADUÇÃO, INTERAÇÕES E COSMOLOGIAS AFRICANAS
}

\author{
Tiganá Santana ${ }^{1}$ \\ 1-Universidade de São Paulo, São Paulo, São Paulo, Brasil
}

\begin{abstract}
Resumo: Aspira-se, neste texto, a que se partilhem reflexões em torno de outras possibilidades para se pensar o traduzir, tendo como base a ideia de interação (desenvolvida pelo escritor-pensador Zamenga B.), à luz de determinadas cosmologias negro-africanas, marcadamente, bantu. Vetores de força de pensares africanos - alguns fundamentais trazidos à tona, na contemporaneidade, por Bunseki Fu-Kiau - ancoram uma análise acerca da ação tradutória, a qual, necessariamente, nesse contexto, não se atém à dimensão mais conhecida como interlinguística. Trata-se de uma dimensão ontológica do traduzir sempre em movimento. Destarte, tal ação, ao representar um relevante acontecimento de interação bantu-africana, figura, geralmente, a transmutação de uma forma-estado de ser noutra forma-estado de ser.
\end{abstract}

Palavras-chave: Traduzir; Interações; Cosmologias Bantu; Transmutação

\section{TRANSLATION, INTERACTIONS AND AFRICAN COSMOLOGIES}

\begin{abstract}
In this text, we hope to reflect on other possibilities to think about translating, based on the idea of interaction (developed by the writer and thinker Zamenga B.), in the light of certain black African cosmologies, markedly, Bantu. Power vectors of African thinking - some fundamental ones brought to light in contemporaneity by Bunseki Fu-Kiau - support an analysis of translation action, which, necessarily, in this context, does not adhere to the dimension best known as interlinguistic. It is an ontological dimension of translating always in motion. Thus, such action, when representing a relevant event of Bantu-African interaction,
\end{abstract}


generally figures the transmutation of a state-form of being into another state-form of being.

Keywords: To Translate; Interactions; Bantu Cosmologies; Transmutation

Façamos, a tempo, uma atualização do título deste artigo. Relacionadas à tradução e às interações coloquemos aqui as cosmologias negras, em lugar das, quiçá, mais bem assentadas cosmologias africanas. Dizer negro, a partir do que foi originalmente proposto por intermédio do encontro entre os poetas e pensadores Aimé Césaire, Léon Damas e Léopold Senghor, e magistralmente deslocado por pensadores como Achille Mbembe, é integrar e entregar as cosmologias, epistemologias, espiritualidades, linguagens e filosofias que têm boa parte da África subsaariana como cabeceira ao movimento transformador próprio da história, das águas, dos ventos e do traduzir. As cosmologias negras às quais podemos recorrer, dentro das nossas reflexões e da densidade da nossa carne, são, simultaneamente, emanações ancestrais, instantes no presente e devir. Não se trata daquilo que não podemos manifestar e realizar, mas, ao contrário, daquilo que, se não incorporarmos hoje, no Brasil, e não colocarmos ao lado dos saberes nativos das florestas ameríndias, deixar-nos-á, necessariamente, mergulhar no profundo poço da repetição irrepetida de uma colonização, mais do que anti-negra, ontológica. Ao pensarmos em cosmologias negras, concedemos que se construíram outras matrizes, por meio dos fluxos diaspóricos, ou seja, não temos nas américas, se quisermos, apenas fragmentos e vestígios de narrativas existenciais egressas de partes do continente africano. Urdiram-se novos sistemas, linguagens, novas materialidades, imaterialidades e impermanências; fizeramse, conforme nos lembra Paul Gilroy, criações inacabadas. Negro e negra concernem a uma retomada da subjugação encaixada na palavra para que, numa radical entorse, proponha-se o seu revés como potência pospositiva ao ato. Atualmente, o desastre que vivemos no país, na sua dimensão, sobretudo, institucional, também se deve ao acirramento da ignorância em relação às mundividências negras e indígenas em todos os setores desse complexo que cha- 
mamos de sociedade brasileira. As pessoas de reflexão e ponderação, em geral, jamais acreditaram, genuinamente, na força dessas epistemologias, negligenciando-as. Poderiam fazer perguntas melhores agora e ter desenvolvido a capacidade de receber da vida as múltiplas respostas, na e da diferença, no contexto da radicalidade real do mundo. A vida poderia ser mais biose do que protocolo e exclusiva efígie de pensares eurocentrados. A hierarquia entre as culturas, a prática discriminatória, as violências assimétricas, a continuidade, enfim, do projeto de uma ideologia hegemônica, por seu grau de parentesco com o humanismo europeu, prevaleceram, sob várias formas e intensidades, inclusive, entre aquelas pessoas que, discursivamente, num sentido mais amplo, condenam as históricas subalternizações exercidas por um certo Ocidente que inventou as raças e os seus lugares e valores respectivos. A experiência radical a ser vivida diante de Outrem, sem pulsão ou razão que o aniquilem, ou, no limite, quando as éticas do dizer formam o cenário onde atuamos e isso é previsto por certos sistemas, estamos diante de outra proposta de experiência humana, em que o humano, assim como as várias formas de ser, é vetor de força que surge das tranças, redes e conjunções. Não cabe aqui conceber, em nenhuma instância, que algo unitário gerara o complexo. Pensar numa origem, de qualquer ordem, é pensar numa relação originária.

Aprendemos com o povo africano kongo ou os bakongo, civilização de tronco linguístico bantu que muito influenciou culturalmente países como o Brasil e Cuba, que a força ontológica primeira, kalunga, é um conjunto de criações que transbordou o vazio (kalunga walunga mbungi); conjunto a partir do qual as coisas passaram a ser. E o que pode designar kalunga?

Os bakongo dizem, principalmente, Kongo Kalunga, Nzambi Ampungo, Nzambi Mpungu, Mpungu Tulendo, para se referir à energia originária que reúne tudo o que existe, surgida a partir de si mesma; energia que completa a si; quintessência da vida (moyo) e do universo (luyalungunu). Afirma o pensador congolês Bunseki Fu-Kiau tratar-se essa energia originária do "sim" (yinga) como presença. Uma pessoa kongo diz kalunga, quando se quer dizer 
presente. Kalunga é, portanto, a dimensão integral de ser (kala). Ainda, segundo Fu-Kiau em African cosmology of the bantu-kongo - principles of life and living: "O mundo, [nza], tornou-se uma realidade física, flutuando em kalunga (na água infinita dentro do espaço cósmico)"1 (20). O caráter líquido de kalunga justifica a sua acepção como "oceano" em kikongo. Mesmo a ideia de uma justificação está em kalunga, haja vista a palavra alunga ser aquilo que é "justificado" ou "completo". Lunga, para Wyatt MacGaffey é "completar", "circunscrever”, e, conforme o dicionário de Português-Kikongo de Francisco Narciso Cobe, é "ter razão". O poeta angolano Abreu Paxe, aliás, classificou ka-lunga como "o lugar da razão". A expressão lunga tiya, em kikongo, quer dizer "fazer o fogo". No dicionário Português-Umbundu, de H.Etaungo Daniel, kalunga, como também em kikongo, vem a significar, numa leitura mais ocidentalizada, "Deus"; "oceano", por sua vez, na língua da mesma família bantu, é okalunga; e a terminação "unga" de esunga ("razão", em umbundu) remete-nos a kalunga, mais uma vez, assim como a palavra para "justificação", asunga. Em kimbundu, língua irmã do kikongo, de acordo com a edição de 1907 do "Diccionario Portuguez-Kimbundu", coordenada pelo médico da Armada Real, J.Pereira do Nascimento, kalunga é "mar", e "ter razão" é lunga por isso, "julgar" é lungisa. Consoante Fu-Kiau (b) em Self-healing power and therapy - old teachings from Africa:

Para as pessoas bantu, Kalunga é a fonte do poder universal que fez todas as coisas acontecerem no passado, faz as coisas acontecerem hoje, e, sobretudo, fará as coisas acontecerem amanhã. Esse poder do todo-no-todo é a vida em si mesma. A ciência não pode explicá-lo, completamente, por ter surgido muito depois que moyo ("vida") passou a existir na Terra ${ }^{2}$. (114)

\footnotetext{
${ }^{1}$ Tradução nossa para o seguinte trecho da obra de Bunseki Fu-Kiau: The world, [nza], became a physical reality floating in kalunga (in the endless water within the cosmic space).

${ }^{2}$ Tradução para: For the Bantu people, Kalunga is the source of universal power
} 
Essa força matricial, por ser um conjunto de forças, ora de um modo, ora de outro, garante-nos a movência, a não concentração ontológica num sujeito, numa configuração.

$\mathrm{Na}$ base do sistema kongo de pensamento, kalunga, que, metaforicamente, em estado líquido, transbordou o vazio e o dominou, apresenta-se-nos como inter-ação. Percebamos, a partir disso, o lugar nuclear da interação enquanto manifestação de um modo de se colocar no mundo. De acordo com o pensador congolês $\mathrm{Za}$ menga B., não há espaços vazios, propriamente, porque o Todo, compõe-se, em verdade, pela interação entre partes e diferenças. Não nos parece que a ideia de totalidade trazida pelos bakongo, sob mediação do referido escritor-pensador, desemboca na anterioridade do Uno em relação às partes que o constituem. O Uno é o conjunto de todas as "coisas" que são, inter-relacionando-se, direta ou indiretamente. Descendemos de interações que não conhecemos e participamos de interações entre o conhecido e o segredado pela vida-morte. O feixe de fundamentos bantu-kongo a desaguar em kindoki, enfim, traz-nos a grande importância, nessa cosmovisão, das interações. "KINDOKI não é outra coisa senão o conjunto das INTERAÇÕES" ${ }^{3}$ (B. 11), em consonância com a afirmação de Zamenga B. ao desvelar uma acepção de totalidade pautada numa grande reunião entre partes que aprioristicamente interagem. Kindoki, ainda que usualmente traduzido apenas como feitiço, faz-se uma expressão potente para designar conhecimento e ciência. Uma vez considerada a poética dos saberes, isto é, se a retomarmos no caráter material do feitiço, podemos ressignificar a palavra a manifestar, muitas vezes, uma perspectiva maniqueísta que nos afasta de diversas chaves não ocidentais de pensamento.

that made things happen in the past, makes things happen today, and above all, will make things happen tomorrow. This all-in-all power is life itself. Science cannot fully explain it, because science was born far after the moyo ("life") came to exist on earth.

${ }^{3}$ Tradução nossa para: KINDOKI n'est autre que l'ensemble des INTERACTIONS. As palavras em caixa alta foram originalmente destacadas pelo autor.

Cad. Trad., Florianópolis, v. 39, n $^{0}$ esp., p. 65-77, set-dez, 2019 
Traduzir com bases feiticeiras é caminhar com as interações; é ter ciência delas. O princípio kindoki, destaca Zamenga B., "manifesta-se na potência da palavra falada" (18). A forma de conhecer e lidar com a palavra falada, desvelamento de intenção, do imaterial, diz de que sorte de feiticeiro se trata. O tradutor-feiticeiro é aquele, no âmbito da linguagem, que recebe, performativamente, o "curso-discurso", a "fala", a qual se configura, conforme descreveu a etnóloga e linguista Geneviève Calame-Griaule, a partir da sua pesquisa entre os $\operatorname{dog}^{4}{ }^{4}$, enquanto:

uma produção do corpo, alguma coisa fabricada pelo corpo e pela pessoa inteira, e que é, com a criança, uma das mais elevadas 'produções' da humanidade. Portanto, a fala se fabrica no corpo. Isso começa por um processo intelectual que se desenrola no cérebro, no pensamento, na ideia primeira da fala. Contudo, a fala, propriamente dita, 'forja-se', eis a palavra que os Dogon empregam, antes, nas vísceras. (24)

A “obra-dita” é curva por ser parábola; vem das vísceras, que são interioridade tátil. O tradutor-ndoki ou tradutor-feiticeiro é um diplomata que serpenteia o seu saber, ao tempo em que se especializa em segredos que não sabe; transita entre os sistemas por necessidade. Toda tradução, para um feiticeiro, será intersemiótica, dado o fato de que será, necessariamente, inter-cosmológica e de que ele lidará com frequências que geram outras formas de introjetar e manifestar mundos. Além de inter-cosmológico, tal traduzir amparado pelas interações (pela ciência florescida nas relações) é trans-cosmológico por ser trânsito entre mundos que constituem o mundo, isto é, entre as faces variadas do mundo. O que as reúne e separa, assim como uniu e separou os territórios africano e

${ }^{4}$ Povos do Mali e Burkina Faso, cujas línguas são, usualmente, classificadas como nígero-congolesas.

Cad. Trad., Florianópolis, v. 39, nº esp., p. 65-77, set-dez, 2019 
americano (de modo, necessariamente, transatlântico como situa a pensadora Beatriz Nascimento), é, mais uma vez, no pensar kongo, kalunga. Segundo esse alicerce de pensamento, a liquidez de kalunga, que também inspira uma compreensão em torno do infinito (enquanto nsensolo), ou seja, daquilo que se expande a partir de um líquido (do verbo sensa), enuncia haver um lado intangível do mundo que, sob a terra, é protegido por seu lado físico e o sustenta, principalmente, por meio dos gênios espirituais simbi. O que se vê é o invólucro do que não se vê. Por seu turno, o invisível dá corpo ao visível, qual todo o ar que há dentro de uma bola de soprar. Essa relação, saibamos bem, jamais se rompe.

A tradução feiticeira retoma, gesta e inventa imagens, já que o viver transatlântico negro constituiu, se sublinharmos, mais uma vez, a reflexão de Beatriz Nascimento, uma experiência de perda de imagem. O dorido apagamento de imagens (principalmente, como códigos) evoca uma emanação ainda maior do que não se vê enquanto fonte de toda a visibilidade nas suas diversas possibilidades e formações. O tempo de espontânea manifestação de kindo$k i$, considerando-se a marcação bantu-kongo dos quatro estágios a conformar um dia vivido - n'seluka, kunda, ndimina e dingidingi - , é o último, também chamado n'dingu a nsi ou, segundo Bunseki Fu-Kiau, "maneira de procurar o mundo". Aqui se trata, rigorosamente, do tempo do silêncio físico e do período de ativação dos sonhos (ndozi), que passam a ser, de modo evidente, os proponentes da mais espessa realidade. O tradutor-ndoki, sonhando, qual água-kalunga, adentra carquilhas, reentrâncias e lados do mundo que se formam na sua presença.

É preciso decodificar, sem dominar, embrulhos resguardados para, assim, traduzir, recodificando. Kolo - código - está na palavra sekola, traduzir. Kolo é também uma forma de se referir ao tempo demarcado, por meio do qual pode existir a experiência humana no continuum do tempo. Cremos que as interações se deem, em grande medida, pela atuação desse tempo contínuo entre os sistemas culturais e ontologias. O tempo contínuo é o lugar de acontecimento dos fatos... todos eles em relação direta ou indireta, 
ainda que as temporalidades sejam distintas dentro desse tempo contínuo, o qual, no fundo, é morada para as coisas serem. O tradutor-ndoki faz oferendas (ngyiekola - e mais uma vez, vê-se o radical tradutório kola) à transmutação que lhe fala. Oferece o seu saber e o seu desconhecimento, igualmente, relevantes para a interpretação de uma narrativa do mundo que, fatalmente, será outra coisa. Só que, nessa operação especificamente negra, levando-se em conta o nosso contexto histórico, há que se considerar as epistemologias que esse mundo originário narrado oferece. Essa anterioridade também nos lega oferendas. Cabe-nos desembrulhar os presentes no presente.

Sem aspirações universalistas, talvez nos caiba, urgentemente, contatar dimensões epistêmicas negras para a reflexão e prática tradutórias. Eis o que chamaríamos de uma tradução negra hoje. Trata-se de estar no funcionamento de um trajeto de traduzir a partir de dentro, de referenciais apresentados pelos próprios sistemas, o que exige de nós uma primeira e profunda translação subjetiva, bem como nos demanda reconhecer a relevância disso para um modo de viver a história. Aliás, a propósito de uma importante ideia de negritude, ensinara Césaire afirmar-se qual uma resposta de entes históricos à história; resposta com raízes na Revolução Haitiana. Tal caminho tradutório nem pede de quem traduz uma escuta passiva do sistema que quer deslocar, nem pode preencher os seus espaços com a imposição tão somente da sua perspectiva, cultura, língua-linguagem. A dança exige manutenção de opacidades (para lembrarmos Édouard Glissant), cuidados em relação ao não visto, ao informe, ao tempo em que nos coloca diante da imprescindibilidade de um posicionamento, uma singularidade, afirmação duma substância condensada. Lemos a tradução negra como uma conjuntura de travessias que se mistura às águas, cortando-as, uma conjuntura de mourões que desmoronam e desmanches que se individualizam indivisíveis. Aqui se vê a retomada da experiência de coletividade em culturas negras: não há nada sem a comunidade, a qual é, em si, o princípio das interações; kalunga é comunidade. Diz uma sentença proverbial kongo que Nzambi mu 
kanda kena: A Totalidade-Ancestral-Sempre-Presente é na comunidade. Nzambi é também kalunga, termos que foram alterados pelo encontro com o cristianismo e traduzidos como Deus, o que implica, a nosso juízo, uma subtração quanto a outras possibilidades para se pensar e experienciar o originário. Perde-se, de novo, para o hegemônico e todo o bioma de possibilidades vira território de monocultura. Nzambi vem a significar acontecimentos, eventos naturais. Tais acontecimentos da natureza, identificamo-los com base numa vivência em comunidade (a incluir o que é e o que não é gente, vazio e preenchimento, sonho e realização). No entanto, esta não desfaz as singularidades; lembra-lhes que não estão em solilóquio e só existem em relação. A ação tradutória, ao lado das artes, talvez seja a prática mais próxima dessa energia-motriz de existir. Sim... porque se encontrar em constante movimento e interrelação de entes, uns absorvendo os outros, transfundindo-se (em termos haroldianos), tudo isso parece ocorrer de modo, criativamente, estético. Kalunga mostra-nos a estética de ser. Notemos a textura de uma terra traduzida por uma árvore que traduz pássaros e ventos. O cromatismo, os sons, os relevos, movimentos, esse desenho pluridimensional, esse texto sinestésico. Para muitas civilizações negras, a estética não é acessória ou um sentido posterior. Parte-se de um território estético que agrega. Por outro lado, a estética é uma dimensão tradutória das estéticas ancestrais de ser, ou seja, os traços sobre um tecido, um oriki (poema sagrado no universo iorubano em África), um instrumento de cordas do Mali, uma máscara, um gesto de realização, a geometria da comida num recipiente traduzem a proposta de kalunga.

A pergunta é: queremos lidar com mundos no mundo ou com línguas? Receamos não haver, ao menos nas dimensões negras a que pudemos ter acesso, um lugar interlinguístico. Pensar em tradução, nesses termos, é pensar em cosmopoiéticas.

No nosso caso específico, como pudemos traduzir sentenças proverbiais bantu-kongo, tendo ciência de que narravam e sintetizavam muitos tempos e construtos de uma comunidade, eram manifestação epistemológica acurada? Só nos restava, cautelosa e 
incautamente, caminhar ao encontro daquela floresta de possibilidades existenciais. $\mathrm{O}$ cuidado se devia ao fato de reconhecermos a autonomia, a força, o acúmulo de saberes, o talhe daquele mundo. O caráter incauto dos nossos passos tradutórios devia-se a não temer o que se poderia apresentar no caminho. Esses pés são para caminhar e descaminhar, numa dinâmica a girar entre a suspensão de juízo e a crítica.

Tomamos como uma sentença central para a nossa reflexão, a seguinte: Kolo diakanga nganga, kutula nganga. A palavra kolo designa código, nó. Mas também é, como já dissemos, uma dimensão temporal; a do tempo marcado, datado, representado por um ícone. Traduzir é lidar com códigos, não, necessariamente linguísticos. Lida-se com códigos de existências. Nganga é quem se especializou em algo. Geralmente, na acepção negro-africana, quem se singularizou num saber, forçosamente, coletivo, o qual deverá, portanto, ser compartilhado, usufruído comunitariamente. Não há outro sentido para o saber, senão ancorar, dinamizar, fazer funcionar e existir uma sociedade. A princípio, os códigos, por serem os fundamentos dessa sociedade, não devem ser devassáveis. Por essa razão, são nós. Oportuna e convenientemente, desembrulham-se os nós para que se desvelem saberes que, automaticamente, velam outros saberes. O especialista não desata mecanicamente um nó. Este se deslinda ao Nganga de certa maneira; com entrega e ressalvas. Entrar num sistema de pensamento, dá-se quando esse sistema também entra em nós; as portas sintonizam-se e abrem-se simultaneamente, não como nado sincronizado porque não é artifício; são fatos sincronizados. Assim, resguardam as suas respectivas impermeabilidades. Justamente, para deixar evidente a importância da opacidade, assim traduzimos a sentença proverbial aludida: Kolo feito só é desfeito por quem sabe o que é kolo. Quem sabe o que é kolo - diz a sentença - pode cifrá-lo e decifrá-lo. E o que é saber? Em kikongo, saber (zaya) é ver (zaya) ou ter consciência (zaya). É preciso que o código (kolo) esteja na consciência de quem com ele lida. Por outro lado, ver, além de zaya (e mona), é tona. Assim, ver é intuir (tona). Intuímos o código, no instante oportuno, e se dá o 
deslocamento-tradução. Sabe o kolo, quem o intui (tona) no âmbito do intelecto (ntona). Intuir é ouvir o que se vê. Disse Fu-Kiau na obra African cosmolgy of the bantu-kongo: "Wa i mona, ye mona $i$ sunsumuka - Ouvir é ver, e ver é reagir/sentir”. (113)

O Brasil perdeu, em 2019, nas artes, além da destacável atriz Ruth de Souza, um dos seus grandes tradutores - os Estados Unidos, por sua vez, perderam a fisicidade de Toni Morrison. Perdeu -o não porque morreu esse tradutor; não se perde alguém a partir da sua morte, ensinam muitas culturas africanas e ameríndias, já que estamos acondicionados dentro de um inescapável sistema de transmutações. O Brasil atual perdeu-o porque não tem podido compreender o que representa traduzir profundezas, gerando outras, aceitando, simples, que somente há o complexo, os co-pertencimentos que passamos a escutar com a demora. Foi-se o tradutor em questão num Brasil de logorreias, re-colonial, não delgado, embrutecido, escatológico de um mundo recém começado. Como dimensionar a relevância da tradução de João Gilberto? Aqui não se trata apenas de música, mas de uma vultosa obra tradutória, que fundou a música moderna (gravada) no Brasil. Tudo porque se criou outra temporalidade e outra estética para lidar com as criações, as narrativas, as enunciações. Eis um traduzir que ativou obras, a partir de outro lugar, e, assim, influenciou as próprias obras e as outras traduções. Mas, antes, porque acontecera uma auto-rotação translacional, ou seja, uma auto-revolução que desloca... e jamais se voltou ao mesmo ponto. É como uma historicidade espiralizada bantu, em que o centro originário encontra-se sempre à vista, mas não se regressa carnalmente a ele. Dada a sua evidência, esse vão originário, como buraco negro, é o grande mistério: que se dance ao seu redor! João Gilberto retirou matéria das obras musicais que registrou e projetou-as, sem equivalentes no mundo fonográfico, à imaterialidade. Concomitante e paradoxalmente, foi a representação material mais densa dessa entrega imaterial. Mas dizia: "o que faço é samba”, dando-nos a prova cabal de que, sem matrizes negras não é possível chegar aos fundamentos, transformar, traduzir o Brasil. Samba é o verbo orar, em kikongo. Talvez, 
na diáspora afro-brasileira, tenha sido alguém a efetivamente sorver o significado e o caráter tão festivo quanto recôndito desse ato complexo e extra-religioso.

Esse tradutor, assim como tudo o que é e vige em kala (ser, acender), foi, afinal, traduzido pela maior das manifestações tradutoras: a morte (fwa, zima - apagar). Traduzir é entrar na floresta da morte (igbo iku), esse lugar iniciático fundamental na cultura iorubana. A morte, mais do que a vida, desvela-nos, dentro do mais radical dos mistérios, o que é traduzir. Chegar ao estágio de pôr-do-sol ontológico, luvemba, é afundir-se no gris (se pensarmos na raiz verbal vemba: agrisalhar-se). O preto e o branco sobrepostos implicam, com eficácia, a fusão da ausência e da presença; na vitalidade da morte, é chegada a compreensão da poiética de kalunga: o seu "sim" de justa presença é, concomitantemente, o "sim" do nada (nesse sentido, também presença). Só não há a não-existência (ndembi kala). Temos, a um só tempo, em instante e infinito, o morrer, o morrerse, o matar, o matar-se; tudo gerando vida ou nos fazendo cantar o canto estético dos pássaros que antecede a aurora.

\section{Referências}

B., Zamenga. Kindoki: source des philosophies et des religions africaines. Kinshasa: Centre de Zabatologie, 1996.

Calame-Griaule, Geneviève; Praline, Gay-Para. La parole du monde: parole, mythologie et contes en pays dogon. Paris: Mercure de France, 2002.

Césaire, Aimé. $O$ discurso sobre a negritude. Tradução de Ana Maria Gini Madeira. Paris: Présence Africaine, 2010. 
Cobe, Francisco Narciso. Novo dicionário Português Kikongo. Luanda: Mayamba, 2010.

Daniel, H. Etaungo. Dicionário português umbundu. Luanda: Mayamba, 2010.

Fu-Kiau, Kimbwandende kia Bunseki. African cosmology of the bantu-kongo: principles of life and living. Nova Iorque: Athelia Henrietta Press, 2001.

Fu-Kiau, Kimbwandende kia Bunseki. Self-healing power and therapy: old teachings from Africa. Clifton: African Tree Press, 2001.(B)

MacGaffey, Wyatt. Religion and society in Central Africa: the Bakongo of Lower Zaire. Chicago: University of Chicago Press, 1986.

Nascimento, J. Pereira do. Diccionario portuguez-kimbundu. Huíla: Typographia da Missão, 1907.

Recebido em: 01/10/2019

Aceito em: 08/11/2019

Publicado em dezembro de 2019

Tiganá Santana.E-mail: tigana@usp.br

ORCID: https://orcid.org/0000-0003-2098-0715 